\title{
Papéis femininos em movimento na constituição do Assentamento Aruega
}

\author{
Arnaldo José Zangelmi \\ Doutorando em Ciências Sociais (Universidade Federal Rural do Rio de Janeiro) \\ arnaldozan@yahoo.com.br
}

\begin{abstract}
Resumo Este artigo tem como objetivo discutir as transformações nos papéis femininos dos trabalhadores rurais envolvidos no processo de constituição do Assentamento Aruega (Novo Cruzeiro/MG). Esse assentamento é resultado direto da primeira ocupação de terra do Movimento dos Trabalhadores Rurais Sem-Terra (MST) em Minas Gerais, em 1988. Seu processo de mobilização desencadeou transformações nas identidades individuais e coletivas que redimensionaram os papéis femininos em relação aos costumes e expectativas tradicionais. Assim, buscou-se demonstrar como, ao atuar nesse movimento social, as mulheres hoje assentadas assumiram uma postura de proeminência, principalmente nas atividades organizativas no Assentamento.
\end{abstract}

Palavras-chave: Assentamentos rurais; identidades; MST; gênero; movimentos sociais.

\section{Introdução} \author{
$\mathcal{E}_{\text {internô a menina, ele falô: }}^{U \text { DECIDI VIM PORQUE ELE [marido] falô que vinha. Ai depois que }}$ \\ - Oh EV, é melhó nós larga isso pra lá, nós não ir. \\ Eu falei: \\ - Não, nós vamo sim! Eu vô buscá a menina e quando a menina ganha alta, nós \\ vai! \\ Eles [mediadores] falô que nós podia ir com 3 ou 4 ou $5 \ldots$ até com 10 dia [depois \\ do dia inicial da ocupação] nós ainda decidia ir. E as menina tudo animada pra \\ vim, mais tudo miudinha e animada pra vim, mais todo mundo animado pra vim. \\ Ai eu tatiei ele... Ele falô assim: \\ - Então nós vamo! (EV, assentada, 53 anos)
}

O Assentamento Aruega (Novo Cruzeiro-MG) é resultado da primeira ocupação de terras do Movimento dos Trabalhadores Rurais Sem-Terra (MST) em Minas Gerais, iniciada em 1988. Sua trajetória foi marcada por intensa mobilização, pressão e resistência contra as autoridades da região, o que tornou esse assentamento um ponto de referência para as ações do MST em Minas Gerais. Seu processo de mobilização, de enfrentamento e de posterior inserção social constituiu identidades relacionadas à interação entre os vários atores envolvidos, como os trabalhadores rurais mobilizados, os mediadores do MST, os representantes do poder estatal e as comunidades locais.

Pretende-se neste artigo discutir a participação das mulheres assentadas nesse processo, demonstrando como essa trajetória está associada ao redimensionamento dos seus papéis na comunidade. Nesse sentido, busca-se demonstrar como, ao atuar nesse movimento social, 
essas mulheres assumiram uma postura de proeminência, principalmente nas atividades organizativas no Assentamento.

Desde o início do trabalho de campo, ${ }^{1}$ com os primeiros contatos, chamou a atenção o fato de mulheres, de várias idades, terem posições de destaque nas atividades do Assentamento. Várias mulheres de Aruega ocupavam posições de liderança, atingiram altos níveis de escolaridade ao estudarem fora, eram chefes de família, o que destoava do papel feminino tradicional. Grande parte dos grupos organizados no Assentamento é dirigida por mulheres ou conta com mulheres em posições importantes na direção.

Essa constatação levou ao questionamento sobre os motivos dessa especificidade em relação ao padrão tradicional de papel feminino, ainda muito presente nessa região, inclusive nas cidades de origem dessas mulheres. Também chamaram a atenção as diferentes interpretações acadêmicas sobre a inserção das mulheres no MST, que poderiam levar a atribuir significados distintos para as experiências observadas em Aruega

Esse trabalho teve a "história oral, de vida e temática", como principal estratégia metodológica, assim como a entendem Amado \& Ferreira (2002). Essa metodologia se mostrou pertinente por contribuir para o acesso às formas de conhecimento não oficializadas e/ ou escritas, pois se movem pela oralidade (Cruikshank, 2002) e estão relacionadas a discursos silenciados diante de relações de dominação. Nesse sentido, as reflexões sobre o caráter social da memória (Halbwachs, 1990) e sua interação com a construção de identidades (Pollak, 1992) também nortearam este estudo.

No tópico a seguir são apresentadas algumas interpretações sobre as mudanças no papel da mulher na atualidade e sobre sua inserção em mobilizações sociais mediadas pelo MST, no sentido de demonstrar como os significados dessas inserções variam de acordo com cada perspectiva, para, assim, levantar alguns questionamentos sobre o processo vivido em Aruega. Em seguida, discute-se parte da história do Assentamento e a participação feminina no processo de luta - que passou pela pressão, enfrentamento, estigma e resistência dos assentados diante de autoridades da região -, demonstrando como essas mulheres têm nessa mobilização uma base importante para suas identidades individuais e grupais.

Assim, pretende-se demonstrar que essa trajetória transformou suas atitudes políticas e princípios organizativos, passando a situá-las como sujeitos (Touraine, 2006) capazes de construir ativamente seu futuro. Nesse sentido, elas consideram a autoorganização como princípio fundamental para a construção de um ambiente comunitário, o que levou à participação atual dessas mulheres na organização do Assentamento. Por fim, demonstra-se que várias mulheres assumiram posição de destaque em grupos organizados no Assentamento e valorizaram essas atividades como base para a continuidade da luta.

\section{Mulheres nos Assentamentos em debate}

Vários estudos recentes têm se esforçado para demonstrar a noção de gênero enquanto construção social, relacional, obscurecida pela naturalização desses papéis constituídos historicamente. Essa naturalização tem contribuído para a manutenção de relações de poder, dominação, que se reproduzem cotidianamente de formas muitas vezes irrefletidas. Saffioti (2004), estudando formas de violência contra a mulher, enfatiza como a ordem patriarcal naturaliza as hierarquias sociais e reproduz desigualdades. Quanto às relações de gênero, a ordem patriarcal tolera $\mathrm{e}$, muitas vezes, incentiva formas de violência contra a mulher, contaminando outras esferas da sociedade e, em grande medida, influenciando nas ações políticas e econômicas.

Para Hirata \& Segnini (2006), a globalização, marcada por políticas públicas neoliberais, trouxe riscos para as condições de trabalho das mulheres, contribuindo numa tendência para a "feminilização" da pobreza. Isso se evidencia no fato de que, a partir dos anos 90, aumentaram, em forma e quantidade, os trabalhos para as mulheres, mesmo que, paralelamente, houvesse a precarização deles. Iasi (2007), também atentando para as questões econômicas, demonstra a relação do trabalho doméstico, exercido principalmente pelas mulheres, com a extração indireta da mais-valia, desvendando uma forma de exploração capitalista obscurecida. O trabalho doméstico agrega valor à força de trabalho, pois, como afirma Iasi, a mantém e reproduz cotidianamente, contribuindo para o processo de acúmulo de capital.

Também percebendo a ideia de gênero como uma construção social, Nobre (2005) discute essas relações na agricultura familiar, que tradicionalmente divide sexualmente o trabalho entre o homem, produtor, e a mulher, reprodutora. Essas divisões, que, como se afirmou anteriormente, não foram superadas no processo de modernização, formam o pano de fundo de grande parte das ações inovadoras no meio rural. 
Nesse sentido, podemos refletir sobre as ações de movimentos sociais no campo, ambiente no qual as relações patriarcais são tradicionalmente mais resistentes na regência das organizações econômicas, sociais e políticas. Cabe questionar até que ponto as mobilizações mediadas por atores políticos organizados se valem dessas relações, reproduzindo-as, ou permitem suas transformações, introduzindo novas práticas e valores.

Alguns autores, argumentando que os papéis femininos têm se modificado substancialmente na atualidade em várias instâncias, buscaram entender esse fenômeno em ligação com transformações amplas, muitas vezes ligadas às práticas dos movimentos sociais, às transformações na organização da ação na modernidade. Giddens \& Pierson (2000) salientam, como parte da reflexividade moderna, a atual "democratização das emoções", na qual, apesar de haver relações de poder, os relacionamentos são mais direcionados para a negociação e para a livre troca, do que para expectativas, papéis e normas tradicionais. Sem a autoridade absoluta da tradição, abre-se espaço para o diálogo, o consenso, a autonomia e a igualdade. A tendência na modernidade é "para relacionamentos baseados muito mais na comunicação afetiva do que em papéis sexuais institucionalmente estabelecidos" (Giddens \& Pierson, 2000, p. 93). Nesse sentido, o papel da mulher se modifica, pois "o caminho para a modernização reflexiva passa necessariamente por uma ampla democracia sexual com todas as oportunidades e também problemas que isso acarreta" (Giddens \& Pierson, 2000, p. 135).

No entanto, existem perspectivas diferentes sobre o teor dessa mudança no papel da mulher em movimentos sociais como o MST. Destaca-se, pela veemência de suas críticas, a perspectiva de Navarro (2002) ao afirmar que existe uma "homogeneização forçada" na militância do MST, o que reduz os espaços para a alteridade, em nome de uma pretensa "causa maior". Existiria, assim, a "subordinação das demandas especificamente femininas" (p. 20). Segundo esse autor,

na história social e política do Movimento tem sido melancólica a trajetória de muitas mulheres portadoras de notáveis talentos pessoais para ocupar posições de liderança, mas não o fazem por que sujeitas ao machismo dominante no interior do MST. Ou, o que é ainda mais perverso, quando assumem o discurso dominante no interior da organização, de certa forma "masculinizam" seu discurso como única forma de manter as posições e poder ascender na estrutura da organização. (Navarro, 2002, p. 21)

Alguns estudos sobre assentamentos caminham também nesse sentido, ao afirmarem a pouca parti- cipação feminina nesses contextos, como enfatizam Rua \& Abramovay (2000, p. 286):

Verifica-se que a relativa equidade entre os sexos, observada no ambiente dos acampamentos, se esgarça e perde significado nos assentamentos, quando a participação feminina se torna surpreendentemente restrita. Os dados sugerem que a baixa participação das mulheres é própria dos assentamentos, não representando um comportamento naturalmente feminino [...]. Se isto ocorre, deve-se às barreiras à participação erguidas a partir das relações sociais e de gênero.

Porém, outros estudos sobre as ações do MST direcionadas para a questão de gênero têm apontado para o diagnóstico de que o Movimento vem contribuindo para a ampliação das possibilidades de participação feminina. Com relação aos avanços do Setor de Gênero no MST, Valenciano \& Thomaz Júnior (2002) salientam o fortalecimento da participação política das mulheres no processo de luta:

A posição ocupada por estas mulheres no MST mostra que a forma como o mesmo encontra-se estruturado, apesar de ainda estar dominado por valores conservadores, fortalece a participação feminina nos espaços de debate e de formação política. No entanto, mais do que desenvolver um trabalho de militância, essas mulheres estão engajadas nas outras esferas do trabalho, como as atividades domésticas e a lida no campo. Apesar de toda a carga de ocupações, essa mulher está presente nas frentes de luta, desempenhando assim a sua terceira jornada de trabalho. Esse envolvimento crescente das mulheres revela que já existe uma alteração significativa nas atitudes de homens e mulheres frente a vários preconceitos sexistas.

O trabalho de Carvalho (2000) também apontou, alguns anos antes de nossa pesquisa, que no Assentamento Aruega as mulheres exerciam um papel inovador. Elas adquiriram maior responsabilidade pela expressão pública familiar, fenômeno percebido pela autora, inicialmente, na aplicação de questionários, quando as mulheres assumiam a responsabilidade de responder pela família. A autora afirma que essa especificidade está associada ao processo de luta, no qual foi criado um espaço de participação. Enfatiza que existe uma grande satisfação pela conquista da terra por parte das mulheres que participaram da mobilização, principalmente por aquelas que foram para a ocupação antes de seus maridos. Segundo a autora,

além de assumirem papéis que historicamente cabem às mulheres casadas do meio rural (cuidar da casa, dos filhos, do quintal), as mulheres do Assentamento têm participação ativa na Comissão de Saúde e nos 
Grupos de Oração. São espaços de trabalho conquistados no Assentamento e que as colocam num nível diferente de conscientização e contribuição na comunidade. (Carvalho, 2000, p. 106)

Coube, então, questionar a experiência das mulheres de Aruega mais profundamente para tentar situar sua participação no processo de constituição, organização e desenvolvimento do Assentamento.

\section{Mulheres na luta por Aruega}

Oh moço, porque a gente entrô na luta e depois eu acho que nunca vô desistir da luta. Porque pra mim a luta foi boa, né, foi pra valê! (EV, 53 anos, assentada)

As cerca de 300 famílias que fizeram a ocupação provieram de vários municípios da região do Jequitinhonha e Mucuri, em Minas Gerais. Essas pessoas moravam em casas pequenas, de pau-a-pique ou madeira, muitas vezes sem luz elétrica e água encanada. Alguns possuíam terra de herança, sempre muito desgastada e pequena em comparação com o grande número de herdeiros. Outros eram assalariados, trabalhavam "a meia" para fazendeiros da região ou eram agregados.

Aruega teve uma mobilização com participação dos mediadores da Comissão Pastoral da Terra (CPT), do Sindicato dos Trabalhadores Rurais (STR) e, principalmente, do Movimento dos Trabalhadores Rurais Sem-Terra (MST). Desde a década de 1970, alguns membros da Igreja Católica e de sindicatos de trabalhadores rurais do Nordeste Mineiro organizavam discussões relativas às injustiças na região (Ribeiro, 1996).

De acordo com os assentados, quando o MST, até então ainda muito restrito à região sul do País, estabeleceu contato com alguns membros dos sindicatos, surgiu a ideia de organizar uma ocupação na região. Desse modo, as reuniões ganharam um caráter mais prático e preparatório. Isso ocorreu alguns meses antes da ocupação, variando a antecedência de acordo com a cidade.

Vários relatos demonstram as dúvidas em relação à viabilidade e segurança desse projeto, pois, como já destacado, se tratava de um empreendimento inovador em Minas Gerais. Por meio das redes sociais de amizade, parentesco e vizinhança -, discutia-se a possibilidade de adesão ao Movimento. Grande parte dos que tiveram contato com essas ideias decidiram não ir, o que nos leva a questionar as motivações para os que resolveram entrar na mobilização.
Nesse ponto, ficou evidente a importância das mulheres, pois, como sugere a citação que serve de epígrafe para a introdução deste artigo, a iniciativa feminina foi decisiva. Apesar de aparecerem publicamente como masculinas, as decisões foram tomadas no ambiente familiar, no qual o envolvimento da mulher e dos filhos era indispensável. EV relatou que tinha decidido ir porque o marido ia, mas ele desistiu após a internação da filha. Porém, EV afirmou: "Não, nós vamo sim! [...] Ai eu tatiei ${ }^{2}$ ele... Ele falou assim: - Então nós vamo!" (EV, 53 anos, assentada). Apesar de a decisão ter sido publicamente dele, a iniciativa de EV foi determinante diante das condições da filha.

A noite escolhida para a ocupação foi a de 12 de fevereiro de 1988, pois era carnaval e a polícia estava ocupada. Caminhões e caminhonetes passaram recolhendo as pessoas, que levavam poucos mantimentos e roupas. Chovia muito, e muitos enfrentaram problemas com a desconfiança da polícia, o que acabou atrasando a chegada ao local da ocupação e aumentando o clima de insegurança.

$\mathrm{Na}$ chegada a Aruega, as barracas de lona foram rapidamente montadas e formaram-se comissões e grupos de trabalho. Havia as comissões de alimentação, saúde, segurança, moradia etc. Num dos barracos, improvisou-se uma escola, que no começo contava com professores do acampamento. Membros dos sindicatos, do MST e da Igreja arrecadavam doações em várias cidades da região para garantir alimentação, remédios, roupas. Havia também uma grande horta coletiva que rapidamente contribuiu para a alimentação.

A ocupação em Aruega rapidamente chamou a atenção das autoridades locais. Fazendeiros da região, prefeito e policiais exerceram forte pressão sobre o Assentamento, independentemente dos processos que corriam na justiça. A pressão mais intensa ocorreu por intermédio da polícia da região. Foram realizadas "vistorias" frequentes em Aruega, além de agressões físicas, sabotagens, perseguições, tentativas de despejo, interrogatórios, bloqueios de alimentação, ameaças. Os policiais acampavam por semanas nas proximidades do Assentamento, tanto para intimidar e gerar desconforto quanto para evitar novas ocupações na região, que era o grande temor dos fazendeiros locais.

Os sem-terra estabeleceram, então, estratégias para conter esse avanço e evitar a entrada de grande número de policiais no Assentamento. Os vigias se organizaram para dar sinal, com foguetes, assim que os policiais se aproximassem. Nesses momentos tensos, as pessoas iam para a única entrada de Aruega e fechavam a passagem. Muitas vezes, para evitar o confronto, as crianças e as mulheres se posicionavam 
na frente, o que deixava a polícia sem possibilidade de ataque direto. Nesse ponto, as mulheres tiveram proeminência nas estratégias de resistência, organizando as crianças e colocando-se na linha de frente de um enfrentamento incerto com policiais desabituados a lidar com mobilizações sociais desse porte, o que poderia trazer resultados trágicos.

Um momento emblemático da resistência em Aruega ocorreu quando a segunda ocupação da região, na Fazenda Sapezinho, foi despejada com ordem judicial. Após esse despejo, aproveitando-se do momento, as autoridades tentaram expandir a ação de despejo também para Aruega, gerando um confronto que até hoje é muito lembrado, no qual os assentados impediram a entrada dos policiais que recuaram frente à multidão perseverante. A pressão policial, após esse acontecimento, foi diminuindo gradualmente.

Das cerca de 300 famílias que participaram da ocupação, 25 foram assentadas em Aruega. Os excedentes foram, em sua maior parte, para o Assentamento Santa Rosa, no município de Itaipé, e para o Assentamento $1^{\circ}$ de Junho, no município de Tumiritinga, no Vale do Rio Doce. Em Aruega, a lembrança sobre essa época em que esses excedentes ainda estavam lá é muito forte, numa época de efervescência, de cantoria, de união e de luta intensa.

Outra forma de pressão sofrida - essa mais contínua e corrosiva - foi o estigma de ladrões de terra, arruaceiros, bandidos, imorais, atribuído pela população da região. Com o passar dos anos, o afastamento dos mediadores do MST e o constante convívio com a cidade, os assentados passaram a ser cada vez mais aceitos como integrantes de Novo Cruzeiro, como pessoas de bem, mesmo que o estigma não tenha se dissipado totalmente.

Evidenciou-se na pesquisa, principalmente nas entrevistas com assentadas, que as mulheres participaram ativamente do processo de mobilização e valorizaram esse processo como parte fundamental de sua trajetória pessoal e coletiva. Uma das entrevistadas, já mencionada anteriormente, que relatou mais profundamente esse processo de luta foi EV, que hoje trabalha como servente na Escola Estadual de Aruega. Ela é reconhecida pelos assentados como uma mulher que vivenciou a resistência em Aruega com muito sofrimento e força.

O momento de entrar na mobilização foi definidor para EV, principalmente diante do temor de ligar-se a um movimento desconhecido em Minas Gerais. O temor e o estranhamento de vizinhos e parentes contribuíram para gerar insegurança, mas a entrevistada demonstra que decidiu ir superando a reprovação de pessoas próximas:

[...] uma pessoa falô comigo: "Oh, Eva, não vai não, porque você num sabe... com certeza você vai passá fome... o policial vai querê pegá vocês lá”. Oh, moço, eu não sei como é que nada...Eu não sei, né. Parece uma coisa mandada por Deus. Eu era tão medrosa...e não fiquei com medo de nada. (EV, 53 anos, assentada)

Os relatos sobre a opressão das autoridades da região, representada pelas frequentes liminares de despejo, também estão muito presentes em seu depoimento:

Foi muito ruim. Muita pressão em cima da gente. $\mathrm{O}$ policial entrava aí, queria que a gente saísse de qualquer jeito. Marcava liminar de despejo pra tirá nós daqui. O policial vinha...Nós não saía. Foi três liminar de despejo que eles marcaram pra despejá a gente daqui. Aí Deus ajudô que o policial veio, mas nós resistimo, não saiu. Falô com ele que nós não saía, que nós tava aqui pra trabalhá. E não saiu de maneira nenhuma. (EV, 53 anos, assentada)

Em várias passagens ela relata as estratégias policiais, como controle de entrada e saída, vistorias inesperadas, interrogatórios constrangedores e ameaças de despejo e violência:

Acho que com medo da gente ocupá mais terra aí, colocô um policial aqui, aqui pra baixo desse... aí perto da ponte. Você viu a ponte, né? Colocô um policial lá pra perseguir a gente, né. Aí, moço, a gente tava aqui sem esperá nada, os policial entrava tudo aqui. E as pessoa ficava [lá fora]. Queria sabê um tanto de coisa, quem [tratava] de nós e não sei o quê [...] Ficava investigando de todo jeito. (EV, 53 anos, assentada)

Outra forma de pressão sentida por ela, como salientamos, foi o estigma, que afetava diretamente a identidade desses trabalhadores. EV conta como sentia esse preconceito:

Nós percebia porque, quando nós ia... porque sempre a gente ia na cidade, né... porque quando nós ia e quando, assim, que a gente tava aqui também, tinha gente lá que fechava até a porta quando ouvia falá que nós [tinha vindo] pra lá. Fechava a porta com medo. Falava que nós era um bocado de assaltante, né, não sei o quê... Pensava um monte de coisa ruim de nós, né. E sendo que nada disso, Ave Maria, nada disso nós num era. (EV, 53 anos, assentada)

Após relatar essa pressão, EV conta como foi a resistência à entrada de policiais no acampamento, reforçando a importância da união e da participação de todos, inclusive mulheres e crianças:

Entrava sim. E a gente não podia falá nada, porque se falasse....Teve um dia que eles entrô aí, bastante, ficô 
bastante, entrô bastante policial. Aí nós juntamo aí na praça, juntô o povo tudo. Aí naquele tempo tava todo mundo aí, aí o povo fez uma assembleia e fez uma roda. Aí quando a gente pegava a cantá, a gritá palavra de ordem, né, eles olhava um pro outro e danava a rir.

[...]Aí ficô um pouquinho, depois foi embora. E teve uma outra época em que eles entrô aqui de novo e aí o povo saiu, né... o povo não, nós, né, saiu com facão, foice, com um tanto de coisa aí. Aí veio a polícia, né, o comandante. Aí quando eles ia passano aqui, o povo veio de lá pra cá, porque nós tinha um segurança aqui nessa casinha. Quando o segurança viu que eles vinha, soltô o foguete e aí o povo ajuntô. Aí eles voltô, não teve coragem de entrá não, voltô de ré. Ainda quase que eles joga o carro ali na barroca. Voltô de ré e foi longe. Oh moço, foi muita pressão viu, foi muita pressão. Só que a gente resistiu, né. (Grifo nosso) (EV, 53 anos, assentada)

EV enfatiza como essa resistência resultou no impedimento de que os despejos fossem efetivados e, em seguida, na conquista da terra. Essa percepção sobre o processo que viveram se repete nos depoimentos de outras mulheres, como CL:

E eu passei muita enfermidade por isso. Eu cheguei aqui eu tava grávida de quatro meses. Vi a hora de morrê com criança e tudo... o sofrimento que nós tava. Passei muita necessidade de alimentação. [...] Aí eu peguei... Ficava naquela luta de madrugada, no frio, nas viagem... passando da hora de alimentá. Acabô que meu filho nasceu doente. [...]. Eu perdi um filho também. (CL, 60 anos, assentada)

A assentada MA também contou sobre a pressão policial, o estigma e a resistência. A falta de tranquilidade para executar tarefas básicas, como cozinhar, é lembrada com angústia:

Aqui nós num tinha sossego nem pra dormi, nem pra comê. Quando a gente tava pensando assim que tava sossegado, o povo vinha com a notícia: “ - Hoje vai ter despejo. Hoje vai ter despejo e você vai ter que ficá prevenindo". Então a gente tava com as panela no fogo e precisava... Nem ânimo a gente tinha mais pra comê, né. Naquela hora...A polícia entrô aqui duas vezes, né. [...] Juntô um bocado de gente ali na praça... foi todo mundo com ferramenta e botou eles pra corrê. Aí eles nunca mais vortô. [...] Oh, moço, eles num gostava de nós não. Nós era os "ladrão de terra. Era ladrão de terra, ladrão de terra". Até aqui por roda de nós o povo chamava nós é de ladrão de terra. (MA, 35 anos, assentada)

GE, outra assentada, nos deu relatos importantes sobre o processo de enfrentamento, no qual policiais praticaram agressões e sabotagens. Relata também a resistência dos assentados, com participação importante de mulheres e crianças, e o estigma sofrido perante o restante dos moradores da região:

Nós ainda tá aqui porque nós somo insistente mesmo! Nós ficô aqui mais de um ano sem podê trabalhá. A gente ia pras roça trabalhá e os policial chegava. Aí a gente chegava e recuava eles. A primeira vez que veio um policial aqui nós tinha chegado... Nós chegô num dia, no outro dia, né, as polícia já chegô. Já chegô pra atacá. Ai nós tava com um fogãozinho feito de barro, né, naqueles murundu. Aí tava fazendo comida. Eu tava com arroz no fogo cozinhano. Aí eles chamaram que as polícia tava lá embaixo.[...] Daí correu todo mundo. Nós com as criança. Essa menina minha que tá de resguardo aí tava com quatro aninho. O SG tava pequeno também. Aí juntô um monte de mulher, menino... os homem. (Grifo nosso)

$[\ldots]$

Depois eles pegô, num achô bão não, veio e... ficô lá mais o povo do acampamento. E o povo usava a água do córrego, né. Aí eles ia lá na cabeceira da água e fazia sujeira... Jogava papel higiênico, jogava papel pra infectá a água [...] Aí nós resistiu, nós ficamo. Teve vez que nós ficô aqui quinze dia com as criança passando fome, porque eles num deixava o caminhão passá com alimentação. Aí a gente pra ir pra rua num podia ir comprá as coisa que tinha barreira de polícia pra todo lado.

$[\ldots]$

O pessoal via a gente assim com mal... Olhava a gente esquisito, estranho...Chamava a gente de ladrão de terra. Aí muitas pessoa num gostava de chegá nem perto da gente, sabe. Se falasse que era de Aruega: “Ó ladrão de terra lá!” Aí a gente ficava constrangido, mas nós num parava não. Nós fazia manifestação, em Novo Cruzeiro o pessoal do sindicato fazia, nós ia. Nós fazia palestra. E falava da importância que tinha da terra, de cada pessoa ter um pedaço de terra. Mas foi muito difícil pra nós, num foi fácil.[...] A gente sentia um pouco de revolta, né. Ficava um pouco envergonhado também. A gente passava num canto e o povo gritava: "Aí vem lá os ladrão!". (Grifo nosso) (GE, 52 anos, assentada)

Esses depoimentos demonstram como essas mulheres assentadas em Aruega passaram por um processo de intensa mobilização, pressão e resistência, que definiu fortemente sua identidade pessoal e a identidade do Assentamento como grupo. Elas viveram ações conjuntas que redefiniram suas noções de direito, justiça social, princípios organizativos, e passaram a se ver como sujeitos (Touraine, 2006) capazes de construir ativamente seu futuro.

Nesse sentido, deram novo significado às suas compreensões sobre as atitudes políticas e, muitas de- 
las, passaram a ver a autoorganização como princípio fundamental para a construção de um ambiente comunitário há muito almejado (Zangelmi, 2007), o que trouxe reflexos para a participação atual de muitas mulheres nos grupos organizados no Assentamento

\section{Mulheres na organização de Aruega}

Ah, eu aprendi mais, assim, sobre os direito da gente, né. Porque onde a gente morava lá a gente era isolado, sabe. Ninguém sabia. Nós às vezes sabia, mais ou menos, algum direito que a gente tinha, mas muitas vezes a gente não podia exigir, né. Pra gente exigir os direito tem que ter uma turma de gente unida. Então eu aprendi que pra gente conseguir as coisa, a gente tem que lutá, junto uns com os otros. (GE, assentada, 52 anos)

Nas primeiras entrevistas em Aruega, realizadas com militantes homens, várias respostas direcionaram os entrevistados para a sugestão de que fosse realizada uma entrevista com EZ, uma senhora de 60 anos que coordena grande parte dos grupos internos. Mulher de CV, um líder reconhecido na mobilização para a ocupação, EZ é vista como alicerce de permanência de muitas atividades comunitárias.

Quando procurada para a entrevista, EZ preferiu que $\mathrm{CV}$ desse o depoimento, pois ele "lembrava melhor da luta". Assim que iniciou a entrevista, ficou claro que $\mathrm{CV}$ era um narrador cativante, lúdico e com ótima memória. Contou sua trajetória, sua entrada na mobilização, como se tornou uma liderança comunitária e a resistência na ocupação. Em seguida, as questões se direcionaram para a organização do Assentamento.

EZ acompanhava a entrevista atenta, preparando o almoço no fogão. Quando questionei CV sobre a existência de missas no assentamento, EZ interveio. Com muita ênfase, ela relatou que havia missas semanais, místicas, encontros que fortificavam a comunidade, principalmente por envolver os jovens. Desse momento em diante, EZ se aproximou e tomou a frente da entrevista. CV consentiu e acompanhou, complementando às vezes.

Nessa entrevista, percebeu-se que EZ considerava que a luta da ocupação não tinha terminado e que a organização das atividades no Assentamento, envolvendo os jovens, para o desenvolvimento de um espírito comunitário seria fundamental para a continuidade da luta. Pela sua postura na entrevista, percebe-se que as- sume essa responsabilidade para si, o que se repete em relação a outras mulheres no Assentamento.

Como parte do trabalho de campo, realizou-se também um diagrama de Venn ${ }^{3}$ com LC e IL, duas irmãs, entre 25 e 35 anos. LC é esposa de um dos principais diretores do Assentamento, e IL uma militante do MST que esteve fora alguns anos para estudar numa escola do Movimento. Ambas participam de grupos organizados e salientam a importância dessas atividades para a comunidade.

Quando questionadas sobre quais grupos atuam no Assentamento, LC e IL lembraram inicialmente dos grupos internos, como as equipes de liturgia, médica, pastorais, cuja base organizativa é formada por mulheres. Essas organizações também foram diagnosticadas pelas assentadas como sendo de maior importância e proximidade com o Assentamento.

Num primeiro momento, a Associação de Aruega foi um grupo naturalmente proposto como mais importante. No entanto, no decorrer da discussão, IL afirmou: "Pra mim, a equipe litúrgica é do tamanho da Associação, a Igreja [risos]. Porque foi o maior sacrifício pra fazer essa igreja, foi com muita luta! E ela não tá pronta ainda".

A construção da igreja é considerada um reflexo de sua luta, principalmente uma luta das mulheres, em contraste com a Associação, cujos principais diretores são homens. Nessa discussão também relataram a importância de a organização no Assentamento participar da direção do Movimento. Segundo IL,

com pouca gente na direção, aí o que que acontece? Aí que a gente tem que brigá pra colocá alguém do Assentamento na direção pra você ter acesso às informações, o que que tá acontecendo lá fora, pra não deixá centralizá. Porque se o pessoal daqui não quiser ir pra direção, acaba centralizando. Não porque eles quiseram, porque nós deixamo.(IL, 35 anos, assentada)

Foi realizado também um diagrama de Venn com o grupo de jovens do Assentamento, denominado "Renascer". Esse grupo conta com a participação de muitas jovens, inclusive na organização. Os resultados dessa dinâmica podem ajudar a perceber a continuidade e transformação, entre as gerações, de princípios organizativos construídos no processo de mobilização e organização do Assentamento.

Nessa dinâmica, evidenciou-se a postura de muitas jovens na tentativa de definir os rumos da ativida-

3. Diagrama de Venn é uma técnica de diagnóstico participativo utilizada para avaliar a importância e a atuação de organizações e grupos que se relacionam com o grupo em questão. Essa técnica se baseia na construção coletiva de respostas para três questões: quais grupos/ organizações atuam no grupo em questão (Assentamento)? Qual a importância dessas organizações para o grupo (tamanho no diagrama)? Qual sua proximidade com o grupo (distância no diagrama)? Constrói-se, assim, uma representação gráfica de círculos identificados com os respectivos grupos. Pela discussão desencadeada por essa atividade, essa estratégia pode ser complementar e potencializadora da história oral (Thiollent, 1986; Faria, 2006). 
de, levando ao registro de grupos internos (de mães, de jovens, litúrgico) e de vários outros núcleos coordenados por mulheres. Atribuíram grande importância a esses grupos, algumas vezes gerando tensão pelo contraste com as formas de organização típicas do MST. No diálogo abaixo, os jovens tentam definir o tamanho (importância) da organização do MST em comparação com o grupo de jovens e núcleos:

TS(mulher): Agora é (a vez da) Diretoria. ${ }^{4}$

JS(homem): Diretoria tem que ser maior que o núcleo.

PZ(mulher): Ela, por enquanto, tá sendo maior que o núcleo, né.[...]

JS: O grupo de jovens é maior que a diretoria.

SG(homem, militante): Não, é a importância. $O$ grupo de jovens não pode ser maior que o MST, maior que a Diretoria e maior que a Brigada!

TS: Uai, num sei não!

(Grifo nosso)

Os argumentos que justificaram a inclusão desses grupos giraram em torno da importância de reforçar laços de sociabilidade no Assentamento. O grupo de jovens se apresentou amplamente nos depoimentos como um foco importante de expressão, organização e continuidade dos anseios comunitários em Aruega (Zangelmi, 2007).

Ficou evidente nas dinâmicas e entrevistas discutidas nesse tópico que as mulheres são responsáveis por grande parte das atividades organizadas no Assentamento. Assumiram para si essa responsabilidade, considerando que eram atividades importantes para a continuidade do processo que vivenciaram na mobilização pela terra, pois fortificaram a comunidade, vincularam as gerações, criaram laços de sociabilidade e podiam ser a base para projetar externamente o Assentamento.

$\mathrm{Na}$ maior parte dos depoimentos, tanto com mulheres quanto com homens, existe uma forte percepção de que os grupos organizados pelas mulheres têm mantido sua vivacidade, enquanto outros, como a Associação, têm demonstrado dificuldades para manter a participação frequente dos assentados. "As reuniões foram esvaziando" ao longo dos anos, segundo afirmam. Nesse sentido, grande parte dos homens tem ampliado sua participação em grupos organizados principalmente por mulheres.

Essa questão está intimamente associada a uma mudança nos padrões de organização do Assentamento. Cada vez mais, atividades referentes à busca pela construção de laços comunitários vêm ganhando força (Zangelmi, 2007). Uma busca pelo ambiente comunitário pode ser visto na ligação entre as atividades organizadas pelos assentados e a rede de sociabilidade, principalmente na constituída em ligação com atividades religiosas.

Essa rede é tanto a base dessas atividades quanto grande parte de seu objetivo. Não é por acaso que grupos muito atuantes no Assentamento - como a Pastoral da Criança, a Equipe de Liturgia e o Grupo de Mães - estão associados às redes de solidariedade da Igreja. Por um lado, essa rede é o alicerce dessas organizações; por outro, ela tira dessas organizações sua vitalidade, sua fluidez e sua continuidade. Nesse sentido, a postura organizada, reflexiva, está a serviço do anseio por um ambiente comunitário mais integrado.

A capacidade de dirigir esforços coletivos, atuar eficazmente, em consonância com a busca tradicional pelo enraizamento numa comunidade, está se dirigindo cada vez mais para esses grupos. Eles são, como se afirmou anteriormente, quase em sua totalidade organizados por mulheres que consideram essas ações fundamentais para a unidade e o desenvolvimento do Assentamento.

\section{Considerações finais}

As mulheres de Aruega participaram ativamente do processo de mobilização, com pressões e resistências, e valorizaram esse processo como parte fundamental de sua trajetória pessoal e coletiva. Elas passaram por experiências que redefiniram suas noções políticas e princípios organizativos, passando a se ver como sujeitos capazes de construir ativamente seu futuro. Assim, assumiram a organização como princípio fundamental para a construção de um ambiente comunitário, o que trouxe reflexos para a participação atual das mulheres nos grupos organizados no Assentamento.

É uma marca de Aruega o redimensionamento do papel da mulher. Ao contrário do que poderia ser suposto, seguindo apenas as obras de Navarro (2002) e de Rua \& Abramovay (2000), grande parte das mulheres em Aruega está em constante rearticulação autônoma de sua função na família e na comunidade, como havia apontado Carvalho (2000). Assim, apesar de as reflexões de Rua \& Abramovay terem valor por apontarem a existência de certo conservadorismo de gênero em práticas do MST - como se pode perceber pelo fato de grupos como a Associação, a Brigada e outros serem tradicionalmente considerados prioritários -, precisamos lançar mão de outros vieses analíti- 
cos para compreender os processos sociais nos assentamentos em suas complexidades e especificidades.

Esse processo vivido em Aruega também vai ao encontro da "democratização das emoções" e da "autonomia moral” que Giddens \& Pierson (2000) caracterizam como atributos da reflexividade moderna. As mulheres do Assentamento têm atualmente maior força para negociar relações, propor novos papéis, para além do que as tradições colocaram como opções para seu gênero.

Apesar de as ações transformadoras das mulheres estarem alicerçadas principalmente na organização da sociabilidade comunitária, o que é atributo tradicional das mulheres - responsáveis pelo cuidado coletivo, da família e da comunidade, em ligação com as redes religiosas, de parentesco e amizade -, elas redimensionam esses papéis ao priorizá-los nos projetos coletivos do Assentamento. E, assim, agregam os flu- xos de decisão tomados anteriormente em ambientes de direção típica masculina. Valorizando suas especificidades, as assentadas passaram a ter maior margem de decisão, inclusive política e econômica, ao contextualizar essas esferas em projetos comunitários mais amplos, em novos focos de construção de diretrizes.

As mulheres de Aruega, ao redefinir seus papéis tradicionais, passaram a delimitar também a trajetória de seu grupo, sua identidade coletiva, empenhandose na busca pelo ambiente comunitário que cada vez ganha mais espaço no Assentamento. Elas foram atores fundamentais no processo de constituição da identidade em Aruega, pautada tanto na rearticulação de valores tradicionais quanto na reavaliação de atividades organizativas típicas do MST (Zangelmi, 2007), numa busca específica pelo enraizamento em que as mulheres constituíram o alicerce e a vitalidade.

\section{Referências}

AMADO, Janaina; FERREIRA, Marieta de Morais. Apresentação. In: ___. Usos e abusos da história oral. Rio de Janeiro: Editora Fundação Getúlio Vargas, 2002.

CARVALHO, Maria da Glória. Lutas e conquistas de camponeses sem-terra: a trajetória dos assentados da Fazenda Aruega. 2000. Dissertação (Mestrado) - Universidade Federal de Lavras, 2000.

CRUIKSHANK, Julie. Tradição oral e história oral: revendo algumas questões. In: AMADO, Janaina; FERREIRA, Marieta de Morais. Usos e abusos da história oral. Rio de Janeiro: Editora Fundação Getúlio Vargas, 2002.

FARIA, A. A. C. Ferramentas do diálogo: qualificando o uso das técnicas do DRP. Brasília: Ministério do Meio Ambiente/ Instituto Internacional de Educação do Brasil, 2006.

FARIA, Nalu; NOBRE, Mirian. (Orgs.). Gênero e desigualdade. São Paulo: SOF, 1997. (Cadernos Sempreviva).

GIDDENS, Anthony: PIERSON, Christopher. Conversas com Anthony Giddens: o sentido da modernidade. Rio de Janeiro: Editora Fundação Getúlio Vargas, 2000.

HALBWACHS, Maurice. A memória coletiva. São Paulo: Vértice, 1990.

HIRATA, Helena; SEGNINI, Liliana (Orgs.). Organização, trabalho e gênero. São Paulo: Editora Senac, 2007. (Série Trabalho e Sociedade).

IASI, Mauro Luis. Ensaios sobre consciência e emancipação. São Paulo: Expressão Popular, 2007.

NAVARRO, Zander. Mobilização sem emancipação: as lutas sociais dos sem-terra no Brasil. In: SANTOS, Boa- ventura de Souza. Produzir para viver. Rio de Janeiro: Civilização Brasileira, 2002.

NOBRE, Miriam. Relações de gênero e agricultura familiar. In: NOBRE, Miriam; FARIAS, Nalu; SILVEIRA, Maria Lúcia. Feminismo e luta das mulheres: análise e debates. São Paulo: SOF, 2005

POLLAK, Michael. Memória e identidade social. Estudos Históricos, Rio de Janeiro: CPDOC, n. 10, 1992.

RIBEIRO, Eduardo Magalhães (Org.). Lembranças da terra: histórias do Mucuri e Jequitinhonha. Contagem: Cedefs, 1996.

RUA, Maria das Graças; ABRAMOVAY, Mirian. Companheiras de luta ou "coordenadoras de panelas"?: as relações de gênero nos assentamentos rurais. Brasília: Ed. Unesco, 2000.

SAFFIOTI, Heleieth I. B. Gênero, patriarcado, violência. São Paulo: Fundação Perseu Abramo, 2004.

THIOllENT, M. Metodologia da pesquisa-ação. São Paulo: Cortez, 1986.

TOURAINE, Alain. Um novo paradigma: para compreender o mundo de hoje. Petrópolis: Vozes, 2006.

VALENCIANO, R.C.; THOMAZ JUNIOR, A. O papel da mulher na luta pela terra: uma questão de gênero e/ou classe?. Scripta Nova: Revista Electrónica de Geografía y Ciencias Sociales, Universidad de Barcelona, v. VI, n. 119, 2002. ZANGELMI, A. J. História, identidade e memória no Assentamento Aruega - Novo Cruzeiro/MG. 2007. 156p. Dissertação (Mestrado em Extensão Rural) - Departamento de Economia Rural, Universidade Federal de Viçosa, 2007. 


\title{
Women's changing roles in the constitution of the Settlement Aruega
}

\begin{abstract}
This article aims to discuss the changes in female roles among rural workers involved in the formation of the Settlement Aruega (Novo Cruzeiro / MG). This settlement is a direct result of the first occupation of land of the Movimento dos Trabalhadores Rurais Sem-Terra (MST) in Minas Gerais, which occurred in 1988. The process of mobilizing triggered transformations in individual and collective identities that redefine the roles women in relation to the customs and traditional expectations. Thus, we sought to demonstrate how, by acting in this social movement, these women have assumed a position of prominence, especially in organizational activities in the settlement.
\end{abstract}

Keywords: rural settlements; identities; MST; gender; social movements.

\section{Nuevas funciones de la mujer en la Constitución de el Asentamiento}

\section{Aruega}

\section{Resumen}

Este artículo tiene como objetivo discutir los cambios en los roles femeninos entre los trabajadores rurales que participan en la formación del Asentamiento Aruega (Novo Cruzeiro / MG). Este es un resultado directo de la primera ocupación de tierras del "Movimento dos Trabalhadores Rurais Sem-Terra (MST) en Minas Gerais", que tuvo lugar en 1988. Su proceso de movilización provocó transformaciones en las identidades individuales y colectivas que redefinen las funciones con relación a los usos tradicionales. Por lo tanto, tratamos de demostrar cóm, actuar en este movimiento social, las mujeres han asumido una posición de prominencia, especialmente en las actividades organizativas en el asentamiento.

Palabras clave: asentamientos rurales; identidades; MST; género; movimientos sociales. 